\title{
Improved Analysis and Modelling of Leakage Inductance for Planar Transformers
}

\section{Ouyang, Ziwei; Hurley, William Gerard ; Andersen, Michael A. E.}

\section{Published in:}

I E E E Journal of Emerging and Selected Topics in Power Electronics

Link to article, DOI:

10.1109/JESTPE.2018.2871968

Publication date:

2019

Document Version

Peer reviewed version

Link back to DTU Orbit

Citation (APA):

Ouyang, Z., Hurley, W. G., \& Andersen, M. A. E. (2019). Improved Analysis and Modelling of Leakage Inductance for Planar Transformers. I E E E Journal of Emerging and Selected Topics in Power Electronics, 7(4), 2225-2231. https://doi.org/10.1109/JESTPE.2018.2871968

\section{General rights}

Copyright and moral rights for the publications made accessible in the public portal are retained by the authors and/or other copyright owners and it is a condition of accessing publications that users recognise and abide by the legal requirements associated with these rights.

- Users may download and print one copy of any publication from the public portal for the purpose of private study or research.

- You may not further distribute the material or use it for any profit-making activity or commercial gain

- You may freely distribute the URL identifying the publication in the public portal 


\title{
Improved Analysis and Modelling of Leakage Inductance for Planar Transformers
}

\author{
Ziwei Ouyang ${ }^{1}$, IEEE Senior Member, William Gerard Hurley ${ }^{2}$, IEEE Fellow, and Michael A.E. Andersen ${ }^{1}, I_{E E E}$ \\ Member
}

1. Department of Electrical Engineering, Technical University of Denmark, Kgs. Lyngby, Denmark

2. School of Electrical and Electronic Engineering, Tianjin University of Technology, Tianjin, China

\begin{abstract}
Planar transformers have often been mistaken to essentially have lower leakage inductances. The "radial effect" is a nature characteristic for planar windings due to a higher aspect ratio of conductor width to conductor thickness, which gives a reduction in leakage inductance. Traditional formulas for leakage inductance in traditional transformers where the winding width is much smaller than the winding height are not suitable for planar transformers. This paper specifically tailors the traditional 1-D solution of leakage inductance by decomposing the leakage flux into longitudinal and transversal flux. In this manner the "eddy current effect" and the "radial effect" in leakage inductance can be analyzed individually. The proposed new formula including both ac (high frequency eddy current effect) and dc effects (radial effect) offers an accurate prediction of leakage inductance in planar transformers. Finite Element Analysis (FEA) and measurements are carried out to validate the proposed formula.
\end{abstract}

Index Terms - leakage inductance, transformer, switched mode power supply, magnetic field.

\section{INTRODUCTION}

Planar magnetics have gained the popularity in recent years because they have several advantages such as low profile, modularity, good thermal characteristics, ease of manufacture, and predictable parasitics etc. [1]-[9]. In traditional wirewound components, it is very difficult to control the winding layout, which means significant variations in leakage inductance and winding capacitance appear in devices manufactured at the same time. On the other hand, with planar magnetics, the windings manufactured by automated PCB machines are more precise and consistent, yielding magnetic designs with highly controllable and predictable parasitic parameters [5]. Developments in wide bandgap devices (such as $\mathrm{GaN}$ and $\mathrm{SiC}$ semiconductors) and in advanced magnetic materials (such as Hitachi ML91S and TDK PC200) push the switching frequency into the $\mathrm{MHz}$ range, to minimize the size of the inductive components, however, the switching loss increases with frequency. PCB windings with enclosed planar magnetic cores have been widely used in such high-frequency and high-power-density converters [6]-[9]. Therefore, an accurate prediction of leakage inductance for planar transformers is needed in order to implement an optimized design in terms of high efficiency. Planar transformers have also been studied in resonant converters, such as LLC converters, where the leakage inductance is critical for a wellmatched resonant frequency [10]-[14].

Characterization and modeling of the planar transformers have been widely published [15]-[28]. Most of the efforts are oriented to obtain winding loss based on modifications to Dowell's formula [15]. Dowell's formula may also be used to find the leakage inductance in conventional transformers [16]. A new set of formulas for calculating self and mutual impedances of planar coil on homogenous ferromagnetic substrates was proposed in [21]. These formulas are well suitable for planar air coils, thick film and thin film cases, but they are not directly applicable to planar PCB transformers where the core encloses the winding. But it is difficult to apply these results to planar PCB transformers. 1-D magnetic component model for planar structures based on transmission lines has been described in [24], [25], and an important characteristic of the "radial effect" for planar transformers has been reported as well. A general 2-D analytical method which is based on the partial-element-equivalent-circuit (PEEC) method was proposed in [30], [31] to compute the window field, and thus to calculate the leakage inductances of planar transformers. Publications [32] and [33] studied the leakage inductance influenced by the high frequency eddy current effect, and accurate expressions of frequency-dependent leakage inductance were proposed. However, these expressions can only be applied in traditional transformer structures where the "radial effect" of planar transformer was not taken into account.

It has often been misunderstanding assumed that planar transformers intrinsically have low leakage inductances compared to that of conventional counter parts. In fact, leakage inductance is proportional with the mean turn length (MTL) of the conductors. Planar transformers intrinsically have a longer mean turn length than that of the traditional vertical structures, resulting in a higher leakage inductance [1]. However, the important benefit of planar transformers in this regard is the relative ease with which primary and secondary windings can be heavily interleaved in a manufacturing or automation environment. Dowell and many of its modified forms for calculating the leakage inductance has been widely applied in traditional wire -wound transformers. However, significant errors have been observed when they are applied to planar transformers. The errors are mainly due to: 1) the traditional analysis only express the leakage inductance at low frequency (with frequency 


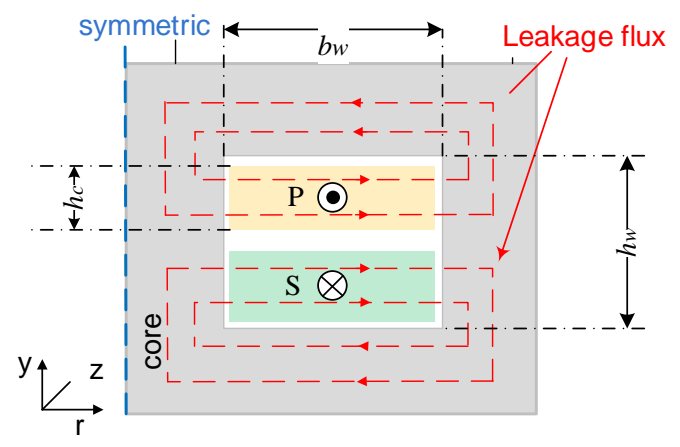

Fig.1 Leakage flux path across half-core window area of a planar transformer.

independency), and the high frequency eddy current effect was not taken into account; 2) the traditional analytical expressions ignores the insulators' thickness between layers because they are so small compared to the thickness of the conductor layers. However, PCB windings usually have much thicker dielectric layers $(>0.2 \mathrm{~mm})$ than the copper thickness. For this reason, the error of the traditional analytical expression can reach to $\sim 30 \%$ or even more [34], depending on the dimensions of the layout; 3) the "radial effect" did not arise in conventional transformers. Planar transformer windings situated in a horizontal plane typically have an extremely high aspect ratio of width to height of a section, causing the currents to concentrate the inner edge, and thus impact on the amplitude of magnetic field tangential to the surface of conductors. A new analytical expression of leakage inductance in planar transformers covering all above 3 considerations especially for the "radial effect" is proposed in this paper. The "radial effect" has been reported in planar transformer modelling before, but it is rare to link it with frequency-dependent leakage inductance calculation. This paper specifically tailors the traditional 1-D solution of leakage inductance calculation by decomposing the leakage flux into longitudinal and transversal flux fields, and thus the "eddy current effect" and the "radial effect" in leakage inductance can be separated. The proposed new formula including both ac (high frequency eddy current effect) and dc effects (radial effect) gives rise to an accurate prediction of leakage inductance in planar transformers.

\section{IMPROVED CALCULATION OF LEAKAGE INDUCTANCE FOR PLANAR TRANSFORMER}

Some flux will leak from the core and return to the air, winding layers and insulator layers, causing imperfect coupling to the secondary winding in a planar transformer as shown in Fig.1. If the secondary is short-circuited, the main flux in the core which links both windings will be negligible because the primary and secondary ampere turns almost cancel. This means only the leakage energy is retained. Assuming that the permeability of core material is infinite $\left(\mu_{r} \rightarrow \infty, \sigma \rightarrow 0\right.$ ), the magnetic field intensity goes to zero inside the core. The magnetic core window height $h_{w}$ is much smaller than the core window width $b_{w}$, and the conductors fully fill the core window width, so that end effects can be assumed to be negligible. The leakage inductance is related to

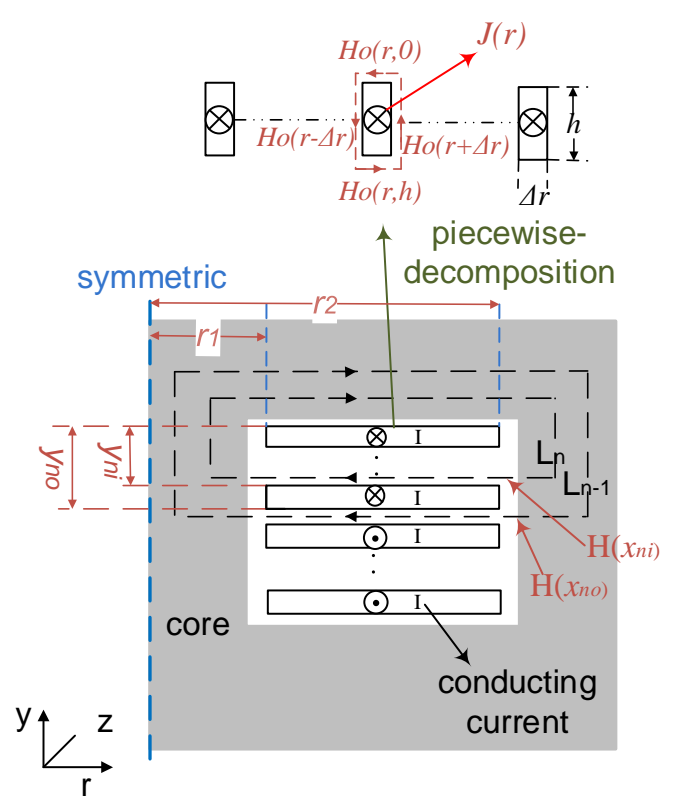

Fig. 2. Inner and outer boundary magnetic field for the $n^{\text {th }}$ layer.

the energy stored in the core window area. Therefore, the magnetic field strength accommodated in the conductors and dielectric insulators are very important to give an accurate account of leakage inductance.

\section{A. Radial Effect}

Planar transformer windings situated in a horizontal plane typically have a very high aspect ratio of width $\left(b_{W}\right)$ to height $\left(h_{c}\right)$ of the conductor cross-section, with the result that the current is concentrated in the inner path due to lower resistance in the shorter path. In any winding with spiral or circular coils conductors, the shorter path on the inside edge (at $r=r_{1}$ in Fig. 2) of the conducting section means that the resistance to current flow is lower and, therefore, the current density is higher than that on the outside. On the basis of this observation, it is reasonable to assume that there is an inverse relationship between the dc current density $J(r)$ and the radius $r$ [35]:

$$
h \int_{r_{1}}^{r_{2}} J(r) \cdot d r=h \int_{r_{1}}^{r_{2}} \frac{k}{r} \cdot d r=I
$$

where $h$ is the conductor thickness, $r_{1}, r_{2}$ are the distances from the center to the inner edge and the outer edge of the core window respectively. The constant $k$ can be obtained from equation (1):

$$
k=\frac{I}{h \cdot \operatorname{In}\left(\frac{r_{2}}{r_{1}}\right)}
$$

Therefore, the dc current density $J(r)$ can be expressed:

$$
J(r)=\frac{I}{r \cdot h \cdot \operatorname{In}\left(\frac{r_{2}}{r_{1}}\right)}
$$

This relationship has been verified by Finite Element Analysis (FEA) simulation as shown in Fig. 6. 


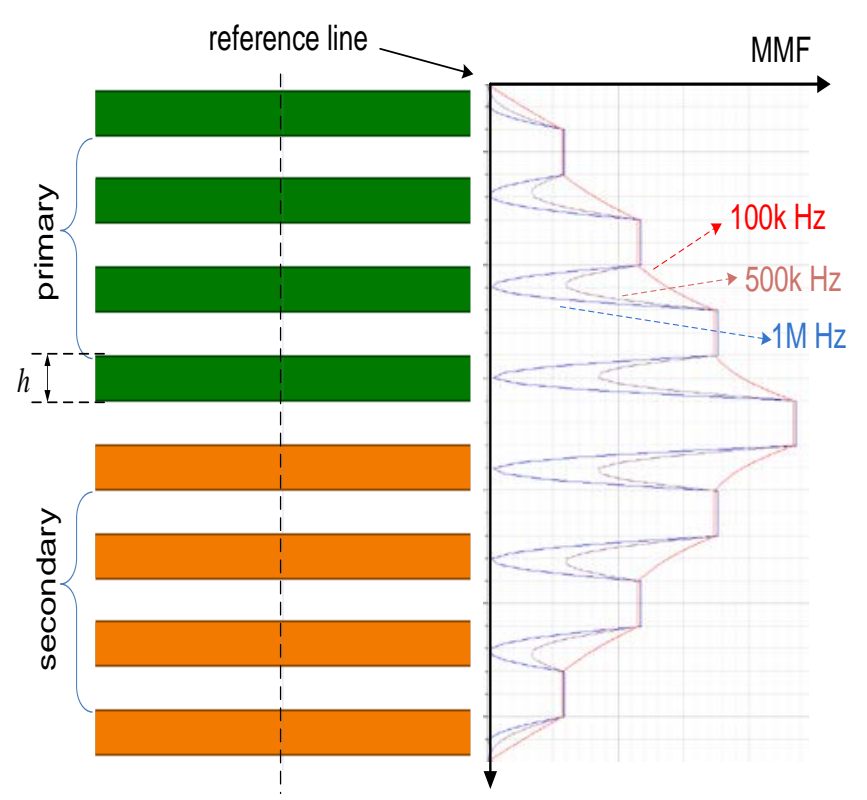

Fig. 3. MMF distribution of planar transformer windings at high frequency (FEA simulation).

\section{B. High Frequency Eddy Current Effect}

We often observe from the measurement that the leakage inductance is reduced when the frequency increases. This is mainly due to the fact that the high frequency effect concentrates the current on the surface of the conductors, and thus equivalently reduces the thickness of the conductors in which the part of leakage energy is stored. The magnetic field is no longer linearly distributed within the conductors at high frequency because of the eddy current effect, this is illustrated in Fig.3. The area of the MMF curve at high frequency is smaller than the one at low frequency, which means the stored leakage energy is actually lower at high frequency.

In a previous contribution [33], the authors gave a concrete analysis in connection to frequency-dependent leakage inductance particularly for traditional transformer structures. Maxwell's equations can be rewritten in Cartesian coordinates as a second-order ordinary differential equation, namely the Helmholtz differential equation:

$$
\frac{d^{2} H_{r}}{d y^{2}}=j \omega \mu_{0} \sigma H_{r}
$$

The general solution of the Helmholtz equation is given by,

$$
H_{r}(y)=H_{1} e^{\gamma y}+H_{2} e^{-\gamma y}
$$

where $H_{1}$ and $H_{2}$ are determined by the boundary conditions and complex constants. The complex propagation constant is:

$$
\gamma=\sqrt{j \omega \mu_{0} \sigma}=\frac{1+j}{\delta_{w}}
$$

and $\delta_{w}$ is the skin depth and $\delta_{w}=\frac{1}{\sqrt{\pi f \mu_{0} \sigma}}$.

However, this analysis only considers the magnetic field along the window height ( $y$-component that is parallel to the surface of conductors). This part of flux is the main contribution to the

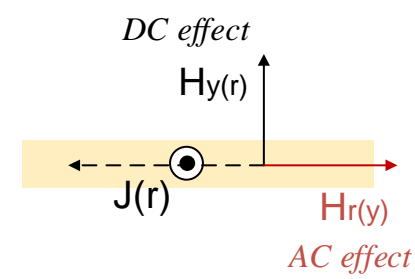

Fig. 4. The magnetic fields due to AC effect and DC effect are decoupled.

high frequency eddy current (AC) effect. The DC current distribution $J(r)$ in equation (3) due to the radial effect induces a magnetic field only having $r$-component, $H_{y}(r)$, (changing along with $r$ axis). The two magnetic fields are orthogonal and decoupled as shown in Fig. 4, so that they can be treated individually. A piecewise decomposition approach is needed to ensure a uniform current distribution in each piece, in order to apply the $r$-component magnetic field $H_{y}(r)$ into the Helmholtz differential equation.

\section{Piecewise Decomposition}

The first conduction layer may be decomposed into many small segments with the width $\Delta r(\Delta r \rightarrow 0)$, as shown in Fig. 2. Taking Ampere's law at radius $r$ :

$J(r) \cdot \Delta r \cdot h=\left[H_{o}(r, 0)+H_{o}(r, h)\right] \cdot \Delta r$

$$
+\left[H_{o}(r-\Delta r)+H_{o}(r+\Delta r)\right] \cdot h
$$

where the magnetic field intensity in the boundary between the first layer and the high permeability core material $H_{o}(r, 0)=$ 0 ; and $H_{o}(r-\Delta r)=-H_{o}(r+\Delta r)$ due to the condition of $\Delta r \rightarrow 0$, this leads to a simplification of equation (7):

$$
H_{o}(r, h)=J(r) \cdot h=\frac{I}{r \cdot \operatorname{In}\left(\frac{r_{2}}{r_{1}}\right)}
$$

Invoking Ampere's law for the closed loops $L_{n}$ and $L_{n-1}$ (see in Fig. 2) in a high permeability core, the upper and lower boundary conditions for the $n^{\text {th }}$ layer of the winding are obtained,

$$
\begin{gathered}
H\left(r, y_{n i}\right)=(n-1) \cdot H_{o}(r, h) \\
H\left(r, y_{n o}\right)=n \cdot H_{o}(r, h)
\end{gathered}
$$

and $y_{n i}$ and $y_{n o}$ are the distance from the upper surface of the first conductor to the upper surface and the lower surface of the $n^{\text {th }}$ layer respectively. Applying the boundary conditions (9) and (10) to the Helmholtz equation (5), the magnetic field inside the $n^{\text {th }}$ layer is obtained:

$$
H(r, y)=H_{o}(r, h) \cdot \frac{n \sinh (\gamma y)+(n-1) \sinh (\gamma h-\gamma y)}{\sinh (\gamma h)}
$$

\section{Leakage Energy in Each Element}

With the consideration of AC and DC effects described above, the double integrals are used to calculate the leakage energy stored in each element. In the corresponding [33] for conventional transformer, this was not necessary since the radial effect was not presented. The differential volume of 
each element is $2 \pi r \cdot d r \cdot d y$, therefore the energy stored in each layer is:

$$
E_{i}=\frac{1}{2} \cdot \mu_{0} \cdot \int_{0}^{h} \int_{r_{1}}^{r_{2}} H(r, y)^{2} \cdot 2 \pi r \cdot d r \cdot d y
$$

Substituting (11) into (12), the energy stored in the primary winding is:

$E_{p}=\sum_{i=1}^{n_{p}} E_{i}=\frac{\mu_{0} \cdot \pi \cdot I_{p}^{2} \cdot n_{p}\left[k_{1}\left(2 n_{p}^{2}+1\right)+4 k_{2}\left(n_{p}{ }^{2}-1\right)\right]}{\operatorname{In}\left(\frac{r_{2}}{r_{1}}\right) \cdot 12 \cdot \gamma \sinh ^{2}\left(\gamma h_{p}\right)}$

where,

$$
\begin{gathered}
k_{1}=\sinh \left(2 \gamma h_{p}\right)-2 \gamma h_{p} \\
k_{2}=\gamma h_{p} \cosh \left(\gamma \cdot h_{p}\right)-\sinh \left(\gamma \cdot h_{p}\right)
\end{gathered}
$$

The same approach can be applied to secondary winding. The expression for the leakage energy stored in the secondary winding $E_{s}$ is similar to equation (13). The dielectric layers are placed between each conducting layer, and the magnetic field inside the $n^{\text {th }}$ dielectric layer remains constant and is equal to the magnetic field of the lower surface of the $n^{\text {th }}$ conductor layer. The energy stored in the dielectric layer is, therefore,

$$
\begin{aligned}
E_{d}=\frac{1}{2} \cdot \mu_{0} \cdot h_{i} \cdot \int_{r_{1}}^{r_{2}} H(r, h)^{2} \cdot 2 \pi r \cdot d r \\
=\frac{\mu_{0} \cdot \pi \cdot h_{i}}{\operatorname{In}\left(\frac{r_{2}}{r_{1}}\right)}\left[I_{p}{ }^{2} \sum_{i=1}^{n_{p}} i^{2}+I_{s}{ }^{2} \sum_{i=1}^{n_{s}-1} i^{2}\right] \\
=\frac{\mu_{0} \cdot \pi \cdot h_{i}}{6 \operatorname{In}\left(\frac{r_{2}}{r_{1}}\right)}\left[I_{p}{ }^{2} \cdot n_{p}\left(n_{p}+1\right)\left(2 n_{p}+1\right)\right. \\
\left.+I_{s}{ }^{2} \cdot n_{s}\left(n_{s}-1\right)\left(2 n_{s}-1\right)\right]
\end{aligned}
$$

where $h_{p}, h_{s}$ and $h_{i}$ are the thickness of primary winding layers, secondary winding layers, and dielectric layer, respectively. The total leakage energy is sum of the energy stored in each elementary layer which can be expressed by:

$$
E_{\text {total }}=E_{p}+E_{s}+E_{d}
$$

For a configuration with one turn in each layer, the turns ratio $n=\frac{n_{s}}{n_{p}}$ is defined, and the thickness of all conductors is kept the same $\left(h_{p}=h_{s}\right)$, then the total leakage inductance is:

$$
\begin{aligned}
L_{l k}=\frac{\mu_{0} \cdot \pi \cdot n_{p}}{3 \operatorname{In}\left(\frac{r_{2}}{r_{1}}\right)}\left\{\frac{n_{p}{ }^{2}\left(k_{1}+2 k_{2}\right)(n+1)}{\gamma \sinh ^{2}\left(\gamma h_{p}\right)}\right. \\
+\frac{\left(k_{1}-4 k_{2}\right)(n+1)}{2 \mathrm{n} \gamma \sinh ^{2}\left(\gamma h_{p}\right)} \\
\left.+\left[2(1+n) \cdot n_{p}{ }^{2}+\frac{1}{n}+1\right] h_{i}\right\}
\end{aligned}
$$

Equation (16) can be also modeled for the case with multiple turns in each layer. It should be noted that more turns in each layer leads to a smaller effect from the dc current distribution.

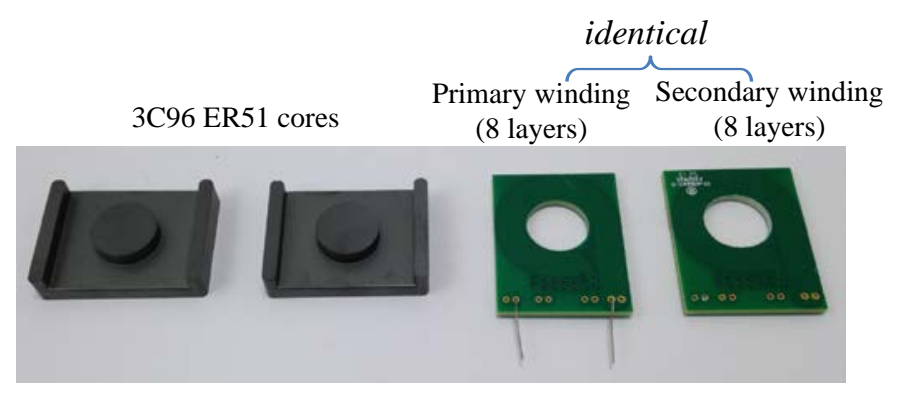

Fig.5. Photos of planar PCB transformer with 8 primary winding turns and 8 secondary winding turns.

Table I Transformer Parameters

\begin{tabular}{|c|c|}
\hline Parameters & Values \\
\hline Number of turns in primary $\left(n_{p}\right)$ & 8 \\
\hline Turns ratio $(n)$ & 1 \\
\hline Primary conductor thickness $\left(h_{p}\right)$ & $0.15 \mathrm{~mm}$ \\
\hline Secondary conductor thickness $\left(h_{s}\right)$ & $0.15 \mathrm{~mm}$ \\
\hline Insulator thickness $\left(h_{i}\right)$ & $0.25 \mathrm{~mm}$ \\
\hline Core type & ER $51 / 10 / 38$ \\
\hline Core material & Ferrite $3 \mathrm{C} 96$ \\
\hline Distance from core center to inner edge $\left(r_{1}\right)$ & $10 \mathrm{~mm}$ \\
\hline Distance from core center to outer edge $\left(r_{2}\right)$ & $20.9 \mathrm{~mm}$ \\
\hline
\end{tabular}

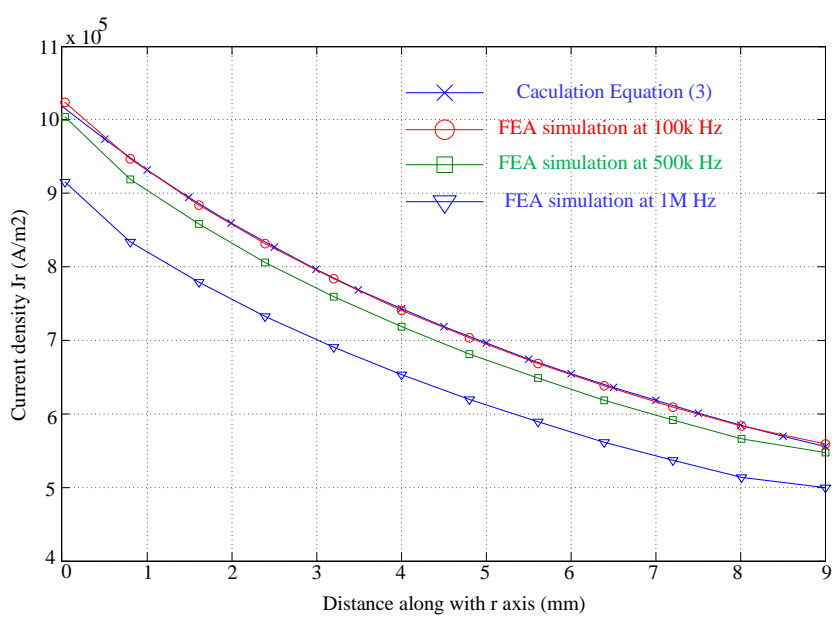

Fig. 6. Current distribution $J_{r}$ along with the $r$ axis for the first conductor layer

\section{FEA SIMULATIONS AND EXPERIMENTAL VERIFICATIONS}

An example of the planar magnetic core ER 51/10/38 was selected to experimentally validate the proposed model for planar transformers. The parameters of the planar transformer are shown in Table I, the actual PCB windings are shown in Fig. 5. Both primary winding and secondary winding have 8 turns with one turn in each layer. The FEA simulation is carried out with ANSYS MAXWELL, and the transformer model is built in a 2D plane under the "eddy current" type.

Fig. 6 and Fig. 7 show the current density along with the $r$ axis (horizontal) and the $y$ axis (vertical), respectively. At low frequency, the current distribution $J_{r}$ along the $r$ axis well matches the equation (3) where the dc current concentrates on 


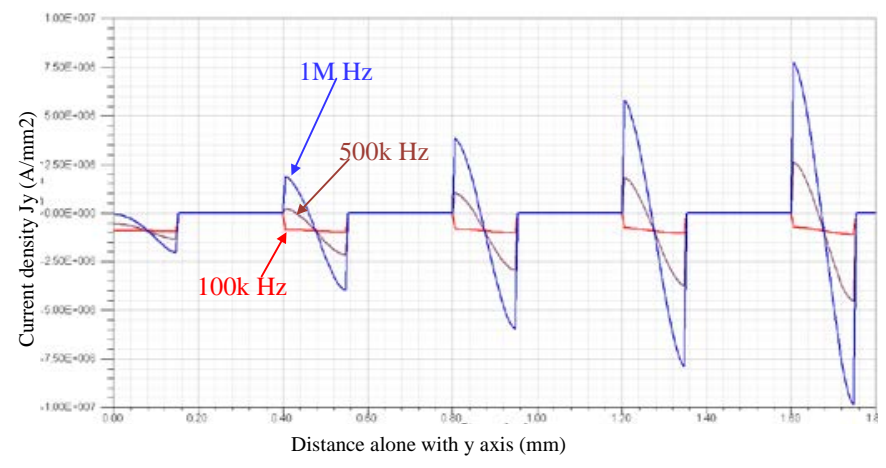

Fig. 7. Current distribution $J_{y}$ along with the $y$ axis for the first five conductor layers.

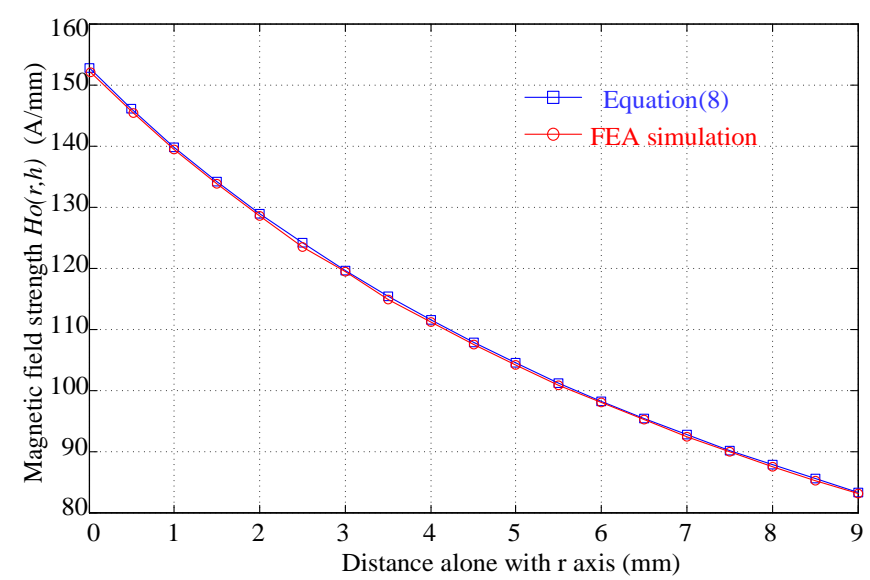

Fig. 8. Magnetic field strength $H o(r, h)$ along with the $r$ axis for the first conductor layer

the inner edge of conductors. At high frequency, the current concentrate on the surface of conductors due to the eddy currents.

Fig. 8 shows the magnetic field strength $H_{o}(r, h)$ of the first conductor layer along with the $r$ axis. The FEA simulation for the magnetic strength matches the equation (8) very well and validates its correctness. Fig. 9 shows the FEA simulation results of the current density $J$ in the conductors. Fig. 9(a) is simulated at $1 \mathrm{MHz}$ with the cylindrical axis in which both the radial effect and the high frequency eddy current effect are included. Fig. 9(b) is simulated at low frequency (dc current) with cylindrical axis which means only the radial effect is included. Fig. 9(c) is simulated at $1 \mathrm{MHz}$ with the Cartesian $\mathrm{XY}$ plane where the radial effect is not included, and only the high frequency ac current effect is included. It may be observed from Fig. 9 that the currents are concentrated on the inner edge of the conductor. The current density $J_{r y}$ can be decomposed into two orthogonal components $J_{r}$ and $J_{y}$. The two components are decoupled in which $J_{r}$ is caused by the radial effect (DC current distribution) due to the unequal impedance path, and $J_{y}$ is caused by the skin and the proximity effects (AC current distribution) due to the transverse flux at high frequency. Fig. 10 shows the measurement results for leakage inductances and ac resistances of the transformer at different frequencies. The measurement was carried out by the

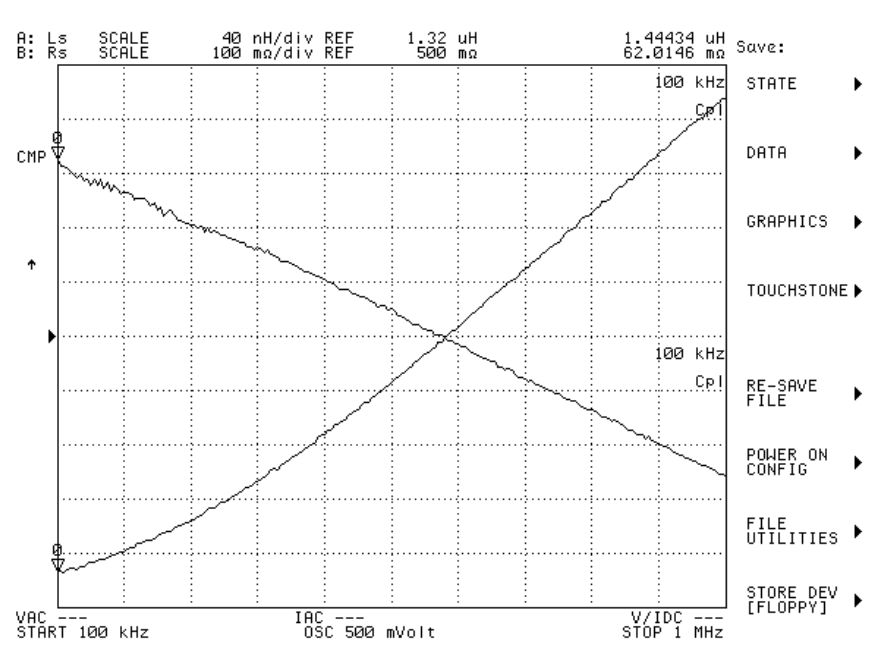

Fig. 10. Measurement results from impedance analyzer HP-4294A.

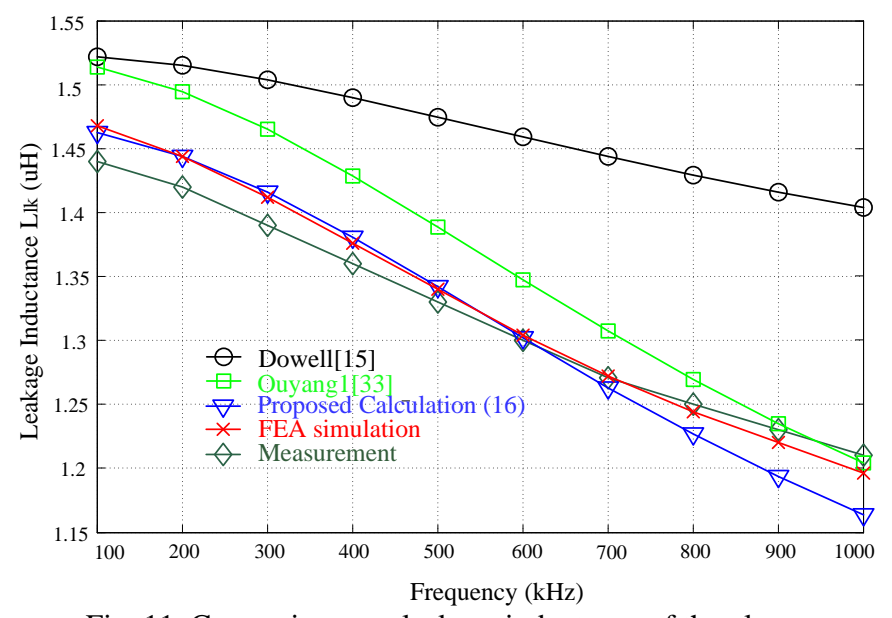

Fig. 11. Comparisons on leakage inductance of the planar transformer.

impedance analyzer HP-4294A. The leakage inductances were obtained by connecting the primary side to the impedance analyzer and shorting the secondary winding. The measured leakage inductances in Fig. 10 are referred to the primary side. $1.44-\mu \mathrm{H}$ leakage inductance is obtained at $100 \mathrm{kHz}$, and $1.22-$ $\mu \mathrm{H}$ leakage inductance is measured at $1 \mathrm{MHz}$. The measurement shows the reduction of the leakage inductances with increased frequencies, this is due to the high frequency eddy current effect. Fig. 11 shows a comparison on leakage inductance between the Dowell's calculation [15], authors' previous work [33], the proposed calculation, the FEA simulation, and the experimental measurement. References [15] and [33] have not taken the "radial effect" into account, and therefore the leakage inductances are overestimated. The overall agreement between the proposed calculation, the FEA simulation, and the experimental measurement is very good.

\section{CONCLUSIONS}

Planar transformer windings situated in a horizontal plane typically have an extremely high aspect ratio, thus concentrating the current in the inner edge of the conductors. 
This phenomenon gives rise to a lower leakage inductance because the area of the stored leakage energy is effectively reduced. This so-called "radial effect" has been reported in planar transformer modelling before, but it is rare to link with frequency-dependent leakage inductance calculation. This paper gives an accurate prediction of leakage inductance for planar transformers with considerations of the high frequency eddy current (AC) effect and the radial (DC) effect. FEA simulations and experimental measurements show good agreement with the predictions. The proposed approach is an improved 1-D solution for leakage inductance, and thus only suitable for the cases that ac magnetic flux is substantially parallel to the surface of rectangular conductors, meaning that the external ac magnetic flux perpendicular to the surface of conductors (2-D consideration) is negligible. The proposed 1$\mathrm{D}$ solution is applicable to most of planar transformers with PCB windings enclosed by high magnetically permeability cores, and it is also applicable for interleaved windings where each layer is interleaved, but not applicable for complex interleaved cases such as primary and secondary windings on the same layer where 2-D consideration may be needed.

\section{REFERENCES}

[1] Z. Ouyang and M. A. E. Andersen, "Overview of planar magnetic technology_fundamental properties," IEEE Trans. on Power Electronics, vol.29, no.9, pp.4888-4900, Sept., 2014.

[2] S. R. Cove, M. Ordonez, F. Luchino and J. E. Quaicoe, "Applying response surface methodology to small planar transformer winding design," IEEE Trans. Ind. Electron., vol.60, no.2, pp.483-493, Feb. 2013.

[3] Z. Ouyang, O. C. Thomsen and M. A. E. Andersen, "Optimal design and tradeoff analysis of planar transformer in high-power dc-dc converters," IEEE Trans. on Ind. Electronics, vol.59, no.7, pp.2800-2810, July, 2012.

[4] M. Pahlevaninezhad, D. Hamza, and P.K. Jain, "An improved layout strategy for common-mode EMI suppression applicable to highfrequency planar transformers in high-power dc/dc converters used for electric vehicles," IEEE Trans. on Power Electronics, vol.29, no.3, pp.1211-1228, March 2014.

[5] W. G. Hurley and W. H. Wolfle, Transformers and Inductors for Power Electronics: Theory, Design and Applicaions, 1st ed. Wiley, 2013.

[6] X. Huang, J. Feng, W. Du, F. C. Lee and Q. Li, "Design consideration of $\mathrm{MHz}$ active clamp flyback converter with GaN devices for low power adapter application," 2016 IEEE Applied Power Electronics Conference and Exposition (APEC), Long Beach, CA, 2016, pp. 2334-2341.

[7] A. Hariya et al., "Circuit Design Techniques for Reducing the Effects of Magnetic Flux on GaN-HEMTs in 5-MHz 100-W High Power-Density LLC Resonant DC-DC Converters," in IEEE Transactions on Power Electronics, vol. 32, no. 8, pp. 5953-5963, Aug. 2017.

[8] C. Fei, F. C. Lee and Q. Li, "High-Efficiency High-Power-Density LLC Converter With an Integrated Planar Matrix Transformer for HighOutput Current Applications," in IEEE Transactions on Industrial Electronics, vol. 64, no. 11, pp. 9072-9082, Nov. 2017.

[9] Y. Liu, A. Kumar, S. Pervaiz, D. Maksimovic and K. K. Afridi, "A highpower-density low-profile DC-DC converter for cellphone battery charging applications," 2017 IEEE 18th Workshop on Control and Modeling for Power Electronics (COMPEL), Stanford, CA, 2017, pp. 16.

[10] J.-M. Choi, B.-J. Byen, Y.-J. Lee, D.-H. Han, H,-S, Kho and G.-H. Choe, "Design of Leakage Inductance in Resonant DC-DC Converter for Electric Vehicle Charger," IEEE Trans. on Magnetics, vol.48, no.11, pp.4417-4420, Nov. 2012.

[11] J. Biela and J. W. Kolar, "Electromagnetic integration of high power resonant circuits comprising high leakage inductance transformers," in Proc. 2004 Power Electronics Specialists Conference, 2004. PESC 04. 2004 IEEE 35th Annual, pp. 4537-4545.
[12] D. Huang, J. Shu and F.C. Lee, "LLC resonant converter with matrix transformer," IEEE Trans. on Power Electronics, vol.29, no.8, pp.43394347, Aug. 2014.

[13] X. Xu, A.M. Khambadkone, T.M. Leong and R. Oruganti, "A 1-MHz zero-voltage-switching asymmetrical half-bridge dc/dc converter: analysis and design," IEEE Trans. on Power Electronics, vol.21, no.1, pp.105-113, Jan. 2006.

[14] J. Jee-Hoon, "Bifilar winding of a center-tapped transformer including integrated resonant inductance for LLC resonant converters," Power Electronics, IEEE Transactions on, vol.28, pp. 615-620, 2013.

[15] P. L. Dowell, "Effects of eddy currents in transformer windings," Proc. Inst. Elect. Eng., vol. 113, no. 8, pp. 1387-1394, Aug. 1966.

[16] E. C. Snelling, Soft Ferrites-Properties and Applications, 2nd ed. London, U.K.: Butterworth, 1988.

[17] J.-P. Vandelac and P. D. Ziogas, "A novel approach for minimizing high frequency transformer copper losses," IEEE Trans. Power Electron., vol. 3, no. 3, pp. 266-277, Jul. 1988.

[18] A. F. Goldberg, J. G. Kassakian, and M. F. Schlecht, "Issues related to 1-10-MHz transformer design," IEEE Trans. Power Electron., vol. 4, no. 1, pp. 113-123, Jan. 1989.

[19] J. Ferreira, "Improved analytical modeling of conductive losses in magnetic components,” IEEE Trans. Power Electron., vol. 9, no. 1, pp. 127-131, Jan. 1994.

[20] W. G. Hurley and D. J. Wilcox, "Calculation of leakage inductance in transformer windings” IEEE Trans.on Power Electronics, vol. 9, no. 1, pp. 121-126, Jan., 1994.

[21] W. G. Hurley and M. C. Duffy, "Calculation of self and mutual impedances in planar magnetic structures," IEEE Trans. Magn., vol. 31, no. 4, pp. 2416-2422, Jul. 1995.

[22] A. M. Pernia, F. Nuno and J. M. Lopera, "1D/2D transformer electric model for simulation in power converters," in Proc. IEEE Power Electron. Spec. Conf., 1995, pp. 1043-1049.

[23] J. P. Keradec, B. Cogitore and F. Blache, "Power transfer in a twowinding transformer: from 1-D propagation to an equivalent circuit," IEEE Transactions on Magnetics, vol. 32, no. 1, pp. 274-280, Jan 1996.

[24] R. Prieto, J. Á Oliver, J. A. Cobos and J.Uceda, "1D magnetic component model for planar structure," in Proc. IEEE Power Electron. Spec. Conf., 1999, pp. 574-579.

[25] R. Prieto, J. A. Oliver, J. A. Cobos, M. Christini, "Magnetic component model for planar structures based on transmission lines," IEEE Trans. Ind. Electron., vol. 57, no. 5, pp.1663-1669, May 2010.

[26] W. G. Hurley, E. Gath, and J. G. Breslin, "Optimizing the AC resistance of multilayer transformer windings with arbitrary current waveforms," IEEE Trans. Power Electron., vol. 15, no. 2, pp. 369-376, Mar. 2000.

[27] C. R. Sullivan, "Computationally efficient winding loss calculation with multiple windings, arbitrary waveforms, and two-dimensional or three dimensional field geometry,” IEEE Trans. Power Electron., vol. 16, no. 1, pp. 142-150, Jan. 2001.

[28] R. Prieto, J. A. Cobos, O. Garcia, P. Alou, and J. Uceda, "Using parallel windings in planar magnetic components," in Proc. IEEE Power Electron. Spec. Conf., 2001, pp. 2055-2060.

[29] J. M. Lopera, M. J. Prieto, A. M. Pernia and F. Nuno, "A multiwinding modeling method for high frequency transformers and inductors," in IEEE Transactions on Power Electronics, vol. 18, no. 3, pp. 896-906, May 2003.

[30] X. Margueron, J. P. Keradec and D. Magot, "Analytical Calculation of Static Leakage Inductances of HF Transformers Using PEEC Formulas," in IEEE Transactions on Industry Applications, vol. 43, no. 4, pp. 884892, July-aug. 2007.

[31] X. Margueron, A. Besri, P. Jeannin, J.-P. Keradec and G. Parent, "Complete analytical calculation of static leakage parameters: a step toward HF transformer optimization," IEEE Trans. on Industry Applications, vol.46, no.3, pp.1055-1063, May-june 2010.

[32] M. A. Bahmani and T. Thiringer, "Accurate evaluation of leakage inductance in high-frequency transformers using an improved frequency-dependent expression," IEEE Trans. on Power Electronics, vol.30, no.10, pp.5738-5745, Oct. 2015

[33] Z. Ouyang, J. Zhang, and W. G. Hurley, "Calculation of leakage inductance for high frequency transformers," IEEE Trans. on Power Electronics, vol.30, no.10, pp.5769-5775, Oct. 2015 
[34] Z. Ouyang, O. C. Thomsen and M. A. E. Andersen, "The analysis and comparison of leakage inductance in different winding arrangements for planar transformer," in Proc. IEEE International Conference on Power Electronics and Drive Systems, pp. 1143-1148, Nov., 2009

[35] W.G. Hurley, M.C. Duffy, Zhang Jun, I. Lope, B. Kunz, W.H. Wolfle, "A unified approach to the calculation of self- and mutual-inductance for coaxial coils in air," IEEE Trans. on Power Electronics, vol.30, no.11, pp.6155-6162, Nov. 2015

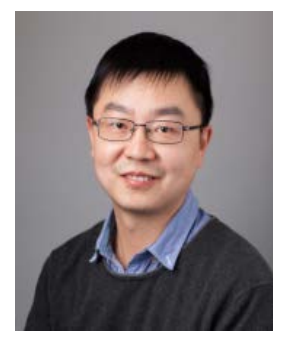

Ziwei Ouyang (S'07, M'11, SM'17) received his $\mathrm{PhD}$ degree from Technical University of Denmark (DTU) in 2011. From 2011 to 2013, he was a postdoc researcher at DTU. From 2013 to 2016, he was appointed as an assistant professor at the same department. Since from April 2016, he is an associate professor at DTU. His research areas focus on high-frequency planar magnetics modeling and integration, high-density high-efficiency power converters, PV battery energy storage system, and wireless charging etc.

He is IEEE senior member. He has over 60 high impact IEEE journal and conference publications, co-author on a book chapter on Magnetics for the "Handbook of Power Electronics" and currently he is the holder of 8 international patents. He was a recipient of Young Engineer Award at PCIMAsia 2014, and received Best Ph.D. Dissertation of the Year Award 2012 in Technical University of Denmark. He received several Best Paper Awards in IEEE sponsored international conferences. He has been invited to give lectures in many universities, enterprises and educational seminars and workshops around the world including USA, Europe and China. He has served as session chair in some IEEE sponsored conferences and associated editor for IEEE Journal of Emerging and Selected Topics in Power Electronics.

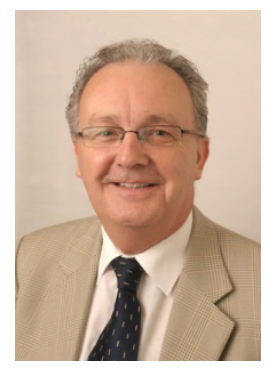

William Gerard Hurley (M'77-SM'90-F'07) received the B.E. degree in Electrical Engineering from the National University of Ireland, Cork in 1974, the M.S. degree in from the Massachusetts Institute of Technology, Cambridge MA, in 1976, the $\mathrm{PhD}$ degree at the National University of Ireland, Galway in 1988 and the higher doctorate D.Eng. degree based on his publications in 2010.

He worked for Honeywell Controls in Canada from 1977 to 1979 and for Ontario Hydro from 1979 to 1983. He lectured at the University of Limerick, Ireland from 1983 to 1991 and was professor of Electrical Engineering at the National University of Ireland, Galway until 2017. He is a Professor at the Tianjin University of Technology under the Foreign Talent Program. He is professor emeritus of Electrical Engineering at the National University of Ireland, Galway. He served on the faculty at the Massachusetts Institute of Technology as a Visiting Professor in 1997/1998.

Research interests include high frequency magnetics, wireless power, and renewable energy systems. Prof. Hurley was General Chair of the Power Electronics Specialists Conference in 2000. He has co-authored a text book on transformer and inductors that has been translated into Chinese. He is the 2013 recipient of the IEEE PELS Middlebrook Award for Technical Achievement. He was appointed Distinguished Lecturer of the IEEE for 2014/17. He received the Harry Owen Award for distinguished service to the IEEE Power Electronics Society in 2018.

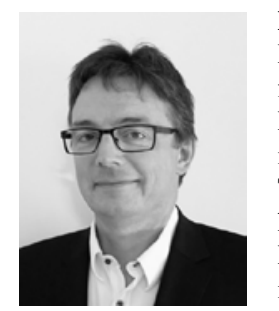

Michael A.E. Andersen (M'88) received the M.Sc.E.E. and Ph.D. degrees in power electronics from the Technical University of Denmark, Kgs. Lyngby, Denmark, in 1987 and 1990, respectively. He is currently a Professor of power electronics at the Technical University of Denmark, where since 2009, he has been the Deputy Head of the Department of Electrical Engineering. He is the author or coauthor of more than 300 publications. His research interests include switch-mode power supplies, piezoelectric transformers, power factor correction, and switch-mode audio power amplifiers. 